\title{
Hypomagnesaemia Posing as Hypoparathyroidism
}

\author{
Sonia Nasreen Ahmad ${ }^{1}$ \\ Received: June 12, 2015 Accepted: July 11, 2015 \\ doi: http://dx.doi.org/10.3329/jemc.v5i3.24752
}

\begin{abstract}
Persistent hypocalcaemia usually is a presentation of hypoparathyroidism. When it is coupled with low parathormone levels the diagnosis seems almost certain. However, the fact that hypomagnesaemia can give rise to both hypocalcaemia and low parathormone levels gives us points to ponder. This case depicts a young woman soon after childbirth presenting with carpopedal spasm and biochemical abnormalities. Subsequent correction of hypomagnesaemia readjusts calcium, potassium and parathormone levels.
\end{abstract}

Key words: Hypomagnesaemia; Hypocalcaemia; Hypoparathyroidism

J Enam Med Col 2015; 5(3): 179-181

\section{Introduction}

Magnesium is mostly present intracellularly in our body. Normal magnesium levels fall between 1.7-2.1 $\mathrm{mg} / \mathrm{dL} .^{1}$ There are two major mechanisms by which hypomagnesaemia can occur: gastrointestinal or renal losses. Whichever the way, a relatively small deficit can cause hypomagnesaemia because there is very little exchange of extracellular magnesium with much larger bone and cell stores. Serum magnesium is not usually measured routinely in clinical practice, hence its deficit takes a longer time to be identified. However, the suspicion should arise in settings of risk factors for hypomagnesaemia (diarrhoea, diuretic use, prolonged use of proton pump inhibitor, alcoholism) or when there is persistent unexplained hypocalcaemia or refractory hypokalaemia. ${ }^{2,3}$ This case history depicts a young female who presented with tetanic spasm and Chvostek's sign positive in the wake of hypomagnesaemia in the post-partum period.

\section{Case report}

A 22-year-old female, with a history of delivery of a healthy baby girl three weeks back, got admitted to our hospital with two weeks fever. The patient presented no other focal symptoms other than generalized weakness. The day after admission the patient complained of facial twitching, muscular cramps and restlessness. On examination, she was conscious, oriented and febrile $\left(100^{\circ} \mathrm{F}\right)$, with a pulse rate of 100 beats per minute and a BP 110/80 mm of Hg. Chvostek's and Trousseau's signs were present. Systemic examination was unremarkable. She had grade 4/5 power in both upper and lower limbs, hypotonia and normal deep tendon reflexes. Plantars were flexors and sensations were normal. There were no meningeal or cerebral signs. All other systems revealed no abnormalities.

Initial blood reports (all reports shown in Table I) showed a neutrophilic leukocytosis along with an ESR of $63 \mathrm{~mm}$ in the first hour. Urine reports were normal. Widal test showed a raised TO titre at 1:160; blood culture yielded no growth. Initial electrolyte reports revealed hypokalaemia but normocalcaemia. The patient was started on potassium replacement therapy as well as intravenous calcium as symptomatic therapy. Despite normal calcium levels, the frequent repetitions of carpopedal spasms prompted a review of the calcium levels from another laboratory one day later along with electrolytes and a serum magnesium screen. The biochemical findings at this stage showed the patient to be hypocalcaemic, hypomagnesaemic and hypokalaemic. A serum parathormone levels and inorganic phosphate level were found below normal and at the 
Table I: Investigation reports of the patient

\begin{tabular}{|c|c|c|c|c|c|c|c|}
\hline Variables & 07.05.15 & 10.05 .15 & 11.05.15 & 12.05 .15 & 14.05 .15 & 16.05 .15 & $\begin{array}{c}24.05 .15 \\
\text { Follow-up }\end{array}$ \\
\hline Haemoglobin & $10 \mathrm{~g} / \mathrm{dL}$ & & & & & & \\
\hline ESR & $63 \mathrm{~mm}$ in $1^{\mathrm{st}} \mathrm{hr}$ & & & & & & \\
\hline WBC & 13400/cu mm & & & & & & \\
\hline Neutrophil & $86 \%$ & & & & & & \\
\hline Platelet & 464000/cu mm & & & & & & \\
\hline Urine $\mathrm{R} / \mathrm{E}$ & Normal & & & & & & \\
\hline S. creatinine & $1.4 \mathrm{mg} / \mathrm{dL}$ & & & & & & \\
\hline $\begin{array}{l}\text { Sodium } \\
(\mathrm{mmol} / \mathrm{L})\end{array}$ & 141 & 140 & 138 & & & & \\
\hline $\begin{array}{l}\text { Potassium } \\
(\mathrm{mmol} / \mathrm{L})\end{array}$ & 2.1 & 2.0 & 5.0 & & & & \\
\hline $\begin{array}{l}\text { Magnesium } \\
(\mathrm{mg} / \mathrm{dL})\end{array}$ & & & $1.69(1.9-2.5)$ & & 3.86 & & 2.08 \\
\hline $\begin{array}{l}\text { Parathormone } \\
(\mathrm{pg} / \mathrm{mL})\end{array}$ & & & & $8.7(12-65)$ & & 54.74 & \\
\hline $\begin{array}{l}\text { Calcium } \\
(\mathrm{mmol} / \mathrm{L})\end{array}$ & $\begin{array}{c}2.24 \\
(2.02-2.6)\end{array}$ & & $\begin{array}{c}1.89 \\
(2.02-2.6)\end{array}$ & & & & 2.37 \\
\hline $\begin{array}{l}\text { I. Phosphate } \\
(\mathrm{mmol} / \mathrm{L})\end{array}$ & & & & $\begin{array}{c}1.10 \\
(0.87-1.45)\end{array}$ & & & \\
\hline ICT Malaria & Negative & & & & & & \\
\hline ICT Kala azar & Negative & & & & & & \\
\hline S. albumin & $2.9 \mathrm{~g} / \mathrm{dL}$ & & & & & & \\
\hline Blood culture & Negative & & & & & & \\
\hline Chest X-ray & Normal & & & & & & \\
\hline USG abdomen & Normal & & & & & & \\
\hline
\end{tabular}

lower limit of normal respectively. Tests following a few days of replacement therapy showed a correction of calcium, potassium and magnesium levels; thereafter parathormone levels came back normal too. The patient's fever subsided on antibiotics and was then discharged; a week later she came for a follow-up with normal electrolytes, calcium and magnesium levels.

\section{Discussion}

Hypomagnesaemia is seen mainly in critically ill patients. It is extremely unusual during pregnancy and the postpartum period. This patient developed functional hypoparathyroidism secondary to hypomagnesaemia in the postpartum period. A similar case of carpopedal spasm in the postpartum period was reported in 1981 in South Africa. That case was complicated by septicaemia due to a retained placenta compounded by diarrohea. ${ }^{4}$ The common cause is loss of magnesium from the gastrointestinal tract or the kidney. Drug-induced hypomagnesaemia, particularly related to proton pump inhibitor (PPI) therapy, is being increasingly recognised. ${ }^{5}$ Other drugs/substances implicated in hypomagnesaemia are alcohol, loop diuretics, aminoglycosides, cisplatinum and amphotericin B. ${ }^{5}$ Another case cited by Singh et al ${ }^{6}$ presented with carpopedal spasm in the light of hypomagnesaemia. However, there was a history of aminoglycoside-induced nephropathy causing renal 
magnesium wasting. Symptoms resolved with withdrawal of the drug and subsequent electrolyte correction. Hypocalcaemia is commonly seen in severe hypomagnesaemia and manifests with tetany as was with our patient. Chronic magnesium depletion can be the result of mild to moderate magnesium wasting and the low levels of total calcium observed are practically due to the effect of hypomagnesaemia on PTH secretion and action. It causes the secretion of PTH to be weakened and/or resistant to its action, thus creating a state of functional hypoparathyroidism. ${ }^{7}$ However, an interesting observation seen in our patient was the low normal phosphate level. It has been noted that in contrast to high phosphate levels that is seen in acquired or idiopathic hypoparathyroidism, phosphate levels are not raised (it remains normal or low normal in patients with hypomagnesaemia). This can be explained by the fact that tissue phosphate deficiency frequently accompanies hypomagnesaemia. ${ }^{8}$ Hypomagnesaemia is an alternative marker of tissue phosphate depletion. Most often hypomagnesaemia can be corrected by oral magnesium salts and patients can be treated at home; in the event of symptomatic hypomagnesaemia intravenous magnesium is warranted.

There are several issues that we faced with this case. Due to limitations in laboratory support and know-how, several points should be kept in mind when facing a situation of carpopedal spasm/muscle twitching with concomitant hypocalcaemia:

1. An immediate arterial blood gas analysis should be carried out in the face of carpopedal spasm to rule out hypocalcaemia induced by respiratory alkalosis.

2. When hypocalcaemia occurs along with hypomagnesaemia, the possibility of the first as a result of the second must be considered. In that case the cause of hypomagnesaemia must be sought out. The three main possibilities are dietary insufficiency, renal loss and drugs (proton pump inhibitors being the commonest culprit).
3. Baseline and subsequent urinary electrolytes should be carried out where possible.

In our patient the exact underlying aetiology could not be established. Financial constraints on part of the patient and lack of certain investigation facilities in the hospital played a major role in this case.

However, strong possibilities lie in the dietary deficiency coupled with increased demand during pregnancy along with the frequent self medication with proton pump inhibitors.

In summary, the learning points achieved from this case are (a) hindrance in the release of PTH and skeletal resistance to its action occurs in severe magnesium deficiency, (b) magnesium has a stimulatory effect on PTH secretion after its proper replacement.

\section{References}

1. Drueke TB, Lacour B. Magnesium homeostasis and disorders of magnesium metabolism. In: Feehally J, Floege J, Johnson RJ (eds). Comprehensive clinical nephrology. $3^{\text {rd }}$ edn. Philadelphia: Mosby, 2007: 136-138.

2. Weisinger JR, Bellorin-Font E. Magnesium and phosphorus. Lancet 1998; 352: 391.

3. Agus ZS. Hypomagnesaemia. J Am Soc Nephrol 1999; 10: 1616.

4. Jialal I, Joubert SM, Norman RJ, Pitsoe SB. Hypomagnesaemia-hypocalcaemia syndrome in the postpartum period. S Afr Med J 1981; 60: 793-794.

5. Hoorn EJ, van der Hoek J, de Man RA, Kuipers EJ, Bolwerk C, Zietse R. Case series of proton pump inhibitor-induced hypomagnesemia. Am J Kidney Dis 2010; 56(1): 112-116.

6. Singh R, Bhat MH, Bhansali A. Hypomagnesaemia masquerading as hypoparathyroidism. J Assoc Physicians India 2006; 54: 411-412.

7. Quamme GA. Renal magnesium handling, new insights in understanding old problems. Kidney Int 1997; 52: 1180-1195.

8. Petts JT. Diseases of the parathyroid gland and other hyperand hypocalcemic disorders. In: Fauci AS, Braunwald E, Kasper DL, Hauser SL, Longo DL, Jameson JL et al (eds). Harrison's principles of internal medicine. $17^{\text {th }}$ edn. McGraw Hill, 2001; 2377-2396. 